\title{
Design and performance evaluation of a device for determination of specific heat capacity of thermal insulators
}

\author{
Sunday Edet Etuk', Ubong Williams Robert ${ }^{2}$ and Okechukwu Ebuka Agbasi ${ }^{3^{*}}$ [D
}

\begin{abstract}
Background: Specific heat capacity is one of the prominent and deciding factors for selection of thermal insulation materials in thermal engineering. In recent times, there has been a great advancement in the manufacturing of a variety of advanced materials in order to meet the modern needs for thermal insulation. Unfortunately, certain drawbacks like high cost of procurement, low accuracy, and limited suitability are associated with the current device that can be used to probe the specific heat capacities of thermal insulators. Thus, there is need to devise a means of addressing the situation. A device, named SEUR's apparatus, was designed, constructed, and used to determine specific heat capacities of some thermal insulators. Measurements were taken on 2 days, and KD2-pro meter was employed to obtain reference values.

Results: The percentage error values in the specific heat capacity of plastic (solid), asbestos, and paperboard were found to be $0.09 \%, 0.14 \%$, and $0.13 \%$ for day 1 measurements and $0.08 \%, 0.17 \%$, and $0.13 \%$ for day 2 measurements, respectively. Reproducibility values of $7.4 \%, 6.4 \%$, and $8.2 \%$ were obtained for the plastic, asbestos and paperboard, respectively. These values fall within the range for unconditional acceptability of a test device.

Conclusion: Results obtained with the use of the SEUR's apparatus are reliable, valid, and of high accuracy. The apparatus is cost-effective and very suitable for use in quick determination of specific heat capacity of porous, nonporous, homogeneous, or heterogeneous thermal insulating materials.
\end{abstract}

Keywords: Calorimetry, KD2-pro meter, SEUR's apparatus, Thermal equilibrium, Thermal insulation

\section{Background}

Thermal insulators refer to materials that are capable of reducing heat when they are in contact with objects or in a range of radiative influence. Nowadays, irrespective of whether thermal insulators (thermal insulation materials) are porous, non-porous, homogeneous, or heterogeneous, they are useful in a wide range of applications in which minimization of unwanted heat losses is a critical consideration. As remarked by [1], thermal insulation is a key component in installations and industrial facilities (especially in pipelines, tanks, heat exchangers) as well as

\footnotetext{
* Correspondence: agbasi.okechukwu@gmail.com

${ }^{3}$ Department of Physics, Michael Okpara University of Agriculture, Umudike, Nigeria

Full list of author information is available at the end of the article
}

building industry, power engineering, chemical process industry, refrigeration, firemanship, and aeronautics. In thermal engineering, one of the prominent and deciding factors for selection of thermal insulation materials is specific heat capacity. The importance of this property is based on the fact that as it gives an indication of how much heat energy is required to heat or cool a particular material of a given mass by one Kelvin change in temperature, it also provides information as to how long the heating or cooling process will take.

There are some laboratory methods that can be used to determine the specific heat capacity of thermal insulators. For example, in calorimetry, method of mixture is one of such techniques. As described by [2, 3], this method involves heating of a solid sample (thermal 
insulator under test) in boiling water for some time after which the sample is quickly transferred into cold water contained in a well-lagged calorimeter. Then after, the mixture is gently stirred until the system attains thermal equilibrium. At this point, the total heat lost by the sample is equated to be the same as the total heat gained by the cold water and calorimeter with stirrer. From the established mathematical relationship, the specific heat capacity of the sample is obtained by calculation. This approach is quick and easy to apply no doubt, but the result may not be of high accuracy unless temperature cooling correction is made [4]. The essence of such correction is to account for the substantial loss of heat to the surroundings due to a relatively large time taken to attain a reasonable fall in temperature of the sample. Apart from the fact that this attempt to improve the accuracy of the results can make the process and, hence, use of this method to be time-consuming, the said technique is not suitable for use if the sample is a porous thermal insulator. This is simply because such sample will absorb some of the hot water and transfer the same to the cold water in the calorimeter, thereby causing a false final mass of water that will consequently increase the level of uncertainly in the results. In that case, heating the porous sample by adopting the approach used by [5] can effectively solve the problem associated with attack by water and yield reliable results. However, porous samples like foam materials may not withstand the chosen furnace temperature suitable for the experimental work.

Another method of calorimetry that may be employed in the determination of specific heat capacity of a thermal insulator is differential canning calorimetry. It is a rapid technique in which a calibrated differential scanning calorimeter is used to determine specific heat capacity by heating a sample and measuring the temperature difference between the sample and a reference. Though the results obtained are reliable, a very small sample mass $(0.5$ to 100 $\mathrm{mg}$ ) is required and the sample under test must be homogeneous [6]. By implication, the specific heat capacity of heterogeneous thermal insulation materials cannot be determined by this technique. This is really a worrisome situation when considering the fact that several fabricated composites that are potential thermal insulators with high-performance efficiency are heterogeneous, and within them, segregation is possible. Also, the instrument in question is very costly, and as such, it is very scarce in many laboratories.

More so, KD2-pro meter is a handheld thermal properties analyzer that may be used for the purpose of quick determination of specific heat capacity of thermal insulators. This device uses transient line heat source method and replaceable sensors to measure thermal properties of materials based on the standard procedure outlined in
[7]. When equipped with a dual needle sensor, it can be used to measure volumetric heat capacity of a test sample [8]. Then after, the specific heat capacity is obtained by taking the ratio of the volumetric heat capacity to the density of the sample. Unlike other thermal needle systems, this device corrects for linear temperature drift which can cause large errors. But before it is used to analyze a solid sample, pilot holes have to be drilled in the sample at $6 \mathrm{~mm}$ spacing for accommodation of the sensors. This may cause very hard samples to fracture, thereby defeating the aim of the experimentation. Also, the fact that it is an expensive device makes it unavailable for use in most laboratories.

It has been observed that as far as the selection of a suitable thermal insulator for a particular application is concerned, specific heat capacity remains one of the vital properties to be probed for a good understanding and proper thermal characterization of the material. Unfortunately, the aforementioned equipment/instruments/devices or methods have certain drawbacks and limitations associated with their use. As such, major setbacks have been suffered in the course of measuring specific heat capacity of assorted thermal insulators (using the available device) in many schools and laboratories. Now that in recent times there has been great advancement in the development/manufacturing of a variety of advanced materials in order to meet the modern needs for thermal insulation, there is need to devise a means of addressing the situation. In this work, therefore, a device herein named SEUR's apparatus is designed, constructed, and used to determine the specific heat capacity of some selected thermal insulators (porous and non-porous, homogeneous and heterogeneous). Reference data will be obtained with the aid of KD2-Pro meter used as a gold standard. In order to establish data quality and ascertain the effectiveness of the SEUR's apparatus, the results obtained by using it will be compared with the reference values generated for the samples.

\section{Description of the SEUR's apparatus}

\subsection{Design and construction}

The SEUR's apparatus is designed to be a device or system that can conveniently house three plates when put to use. In addition to the sample under investigation, one of such plates is of a metallic material (e.g., aluminum or copper) while the other one is of a nonmetallic solid material (e.g., plywood) of known specific heat capacity. These plates are meant to act as accessories for heat exchange. Though their thickness may vary very slightly, they are cut to be of the same length and breadth. The apparatus is made in the form of a box using two halves of polished hardwood $16 \mathrm{~mm}$ thick. Externally, each half measures $107 \mathrm{~mm}$ in length, $30 \mathrm{~mm}$ in width, and $110 \mathrm{~mm}$ in height. The two halves are joined 
at one end by means of two small hinges to ease in opening and closing when need arises. Also, the surfaces of the inner cavity provided for heat exchange are covered with cork of thickness $6 \mathrm{~mm}$ and then lagged thickly with fiberglass (Fig. 1) so as to minimize heat losses. In doing so, a square space measuring $6 \mathrm{~mm} \times 6$ $\mathrm{mm} \times 3 \mathrm{~mm}$ is carefully and centrally provided such that when the apparatus is closed and clamped, the plates are tightly embedded without making contact with the wooden frame. Again, one pilot hole is drilled at the center of each half as well as the middle of the top of the apparatus for accommodation of type- $\mathrm{K}$ digital thermometer probe needed for temperature monitoring and measurements. In all, three thermometers are needed for use in such a way one is assigned to monitor and measure the temperature of a particular plate.

\subsection{Operation}

The working of this device is based on the principle of conservation of energy [9]. The three plates selected for use are first weighed and their masses noted. Also, the initial temperature of the test sample and that of the non-metallic plate are noted. Care has to be taken to ensure that the probes or thermometers are not interchanged. After heating of the metallic plate to about 60 ${ }^{\circ} \mathrm{C}$, it is transferred using tongs and sandwiched between the test sample and the non-metallic plate. Immediately that is done, its temperature is noted and the device is closed and clamped. With the other thermometer probes inserted and connected to separate thermometers (Fig. 2), the temperature values of the plates can be monitored simultaneously until the system attains thermal equilibrium. At that instant, the temperature of each plate is noted and it can be assumed that the total heat lost by the metallic (hot) plate is equal to the sum of the quantities of heat gained by the other plates.

Now, let $M_{c}, M_{b}$, and $M_{s}$ be the mass of the metallic plate, non-metallic plate, and test sample, respectively.

Also, let $C_{c}, C_{b}$, and $C_{s}$ be their specific heat capacity, respectively.

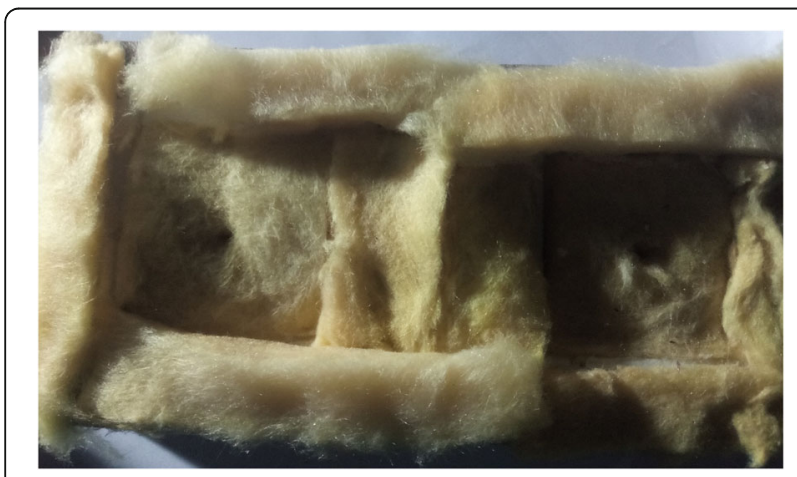

Fig. 1 Internal features of the SEUR's apparatus
Again, let $\theta_{2}$ and $\theta_{3}$ be the initial temperature of the non-metallic plate and test sample, respectively, when the metallic plate is sandwiched at $\theta_{1}$ between them.

Since the quantity of heat associated with a substance can be calculated as the product of mass, specific heat capacity, and change in temperature of the substance $[10,11]$, it follows in this case that

$$
M_{c} C_{c}\left(\theta_{1}-\theta_{4}\right)=M_{b} C_{b}\left(\theta_{5}-\theta_{2}\right)+M_{s} C_{s}\left(\theta_{6}-\theta_{3}\right)
$$

from which

$$
C_{s}=\frac{M_{c} C_{c}\left(\theta_{1}-\theta_{4}\right)-M_{b} C_{b}\left(\theta_{5}-\theta_{2}\right)}{M_{s}\left(\theta_{6}-\theta_{3}\right)}
$$

where $\theta_{4}, \theta_{5}$, and $\theta_{6}$, respectively, represent the temperature of the metallic plate, non-metallic plate, and test sample plate at thermal equilibrium of the system.

\section{Materials and method}

The materials used in this work were aluminum $(4 \mathrm{~mm}$ thick), copper ( $4 \mathrm{~mm}$ thick), plastic (3.5 $\mathrm{mm}$ thick), asbestos (4 $\mathrm{mm}$ thick), birch plywood ( $3.175 \mathrm{~mm}$ thick), and paperboard. Whereas other materials were obtained from their respective vendors within Uyo metropolis in Akwa Ibom State, Nigeria, the paperboard was prepared by shredding paper and then soaking the pieces in warm water for $10 \mathrm{~h}$ after which the soaked pieces were pounded into paste. This was followed by compression of the paste in a $610 \mathrm{~mm} \times 610 \mathrm{~mm} \times 3 \mathrm{~mm}$ mold to form the board. All the materials were dried completely and also made to be dust-free before each of them was cut into $60 \mathrm{~mm} \times 60 \mathrm{~mm}$ square plate. In the cases of the aluminum and copper, one plate each was made. Also, ten pieces of plate were produced from each of the test samples (plastic, asbestos, and paperboard), and 15 plate pieces were prepared from the plywood. The plates were coded for easy identification. In order to assess the reproducibility of the SEUR's apparatus, measurements of specific heat capacity of each test sample plate were performed on two different days with some varied conditions.

On the first day, 5 plate pieces of each test sample, the aluminum plate, and the plywood plates were made use of. The mass of each of them was measured with analytical balance (METTLER TOLEDO - 203). Also, three digital thermometers (model no. 305) were calibrated and used for temperature measurements by means of type- $K$ probe. Again, heating of the aluminum plate was done with the aid of an electric oven set at $60{ }^{\circ} \mathrm{C}$. Two trial runs were carried out for each test sample plate in orderly manner and then at random. Each test sample plate was assigned a separate plywood plate. On the second day, the procedure was repeated in a different 


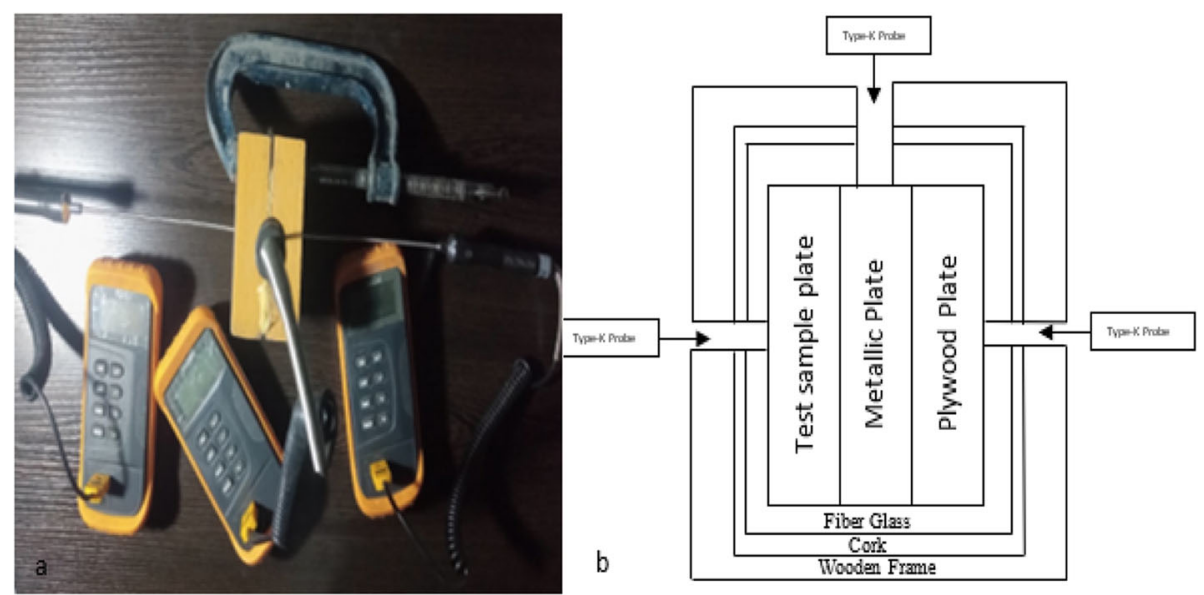

Fig. $\mathbf{2}$ a View of the SEUR's apparatus in use. b Schematic representation of measurement setup

laboratory unit. In this case, all the plywood plates were used with the copper plate and remaining 5 plate pieces of each test sample.

On both days, the SEUR's apparatus was used for the determination of the specific heat capacity of a test sample plate before the reference value for the same plate was determined by means of KD2-pro meter. Two techniques, namely geometry method and modified water displacement method, were employed to determine the volumes of the non-porous sample plates and porous sample plates, respectively, before their corresponding density was calculated [12]. Then after, the specific heat capacity value was computed thus

$$
C_{s}=\frac{C_{v}}{\rho}
$$

where $C_{v}$ and $\rho$ represent the volumetric heat capacity and density, respectively, of the sample plate under test.

All the tests in this work were performed at room temperature with $\pm 2{ }^{\circ} \mathrm{C}$ variations, and the results were tabulated and analyzed.

\section{Results}

The parameters and specific heat capacity values of each of the test sample plates are registered in Table 1. Also, the mean values of the specific heat capacity of each test sample obtained with respect to day 1 measurements are recorded in Table 2. In both presentations, the results of specific heat capacity determination obtained by using the SEUR's apparatus are regarded as the measured values, and their counterparts got by the use of KD2-pro meter are taken to be the reference values.

\section{Discussion}

From Table 1, it can be seen that for a particular test sample, the specific heat capacity decreases as the plate's density increases. Since mass contributes significantly to a material's density, this may be due to the slight variations observed in the masses of the test sample plates. Also, it can be observed that though the volumetric heat capacity value is the same for some plates of a test sample, the reference values of specific heat capacity in such situation are not exactly the same. This is possible because volumetric heat capacity is a function of density, and in the cases in question, the obtained density values vary slightly in direct trend with the plate's masses. Again, for each test sample, the specific heat capacity values obtained on day 1 are not the same as the values got on day 2. In the case of the measured values, the mean results recorded yield $5.98 \mathrm{Jkg}^{-1} \mathrm{~K}^{-1}, 4.37 \mathrm{Jkg}^{-1}$ $\mathrm{K}^{-1}$, and $4.87 \mathrm{Jkg}^{-1} \mathrm{~K}^{-1}$ as range values for the plastic, asbestos, and paperboard, respectively. Obviously, these values differ from the corresponding range values of $1.36 \mathrm{Jkg}^{-1} \mathrm{~K}^{-1}, 0.85 \mathrm{Jkg}^{-1} \mathrm{~K}^{-1}$, and 0.54 $\mathrm{Jkg}^{-1} \mathrm{~K}^{-1}$ deduced from the reference values.

However, Pearson's product-moment correlation test performed at 0.05 level of significance between the reference values and mean measured values gives coefficients for the plastic, asbestos, and paperboard as $0.9429,0.9138$, and 0.9398 for day 1 results as well as $0.9841,0.8418$, and 0.8509 for day 2 results, respectively. These coefficients clearly indicate that there exists a very strong positive relationship between the specific heat capacity values determined by means of the SEUR's apparatus and those obtained by using KD2-pro meter. At $p<0.05$, the results of one-way analysis of variance reveal that neither the mean measured specific heat capacity values nor the reference 
Table 1 Parameters and specific heat capacity of each test sample plate

\begin{tabular}{|c|c|c|c|c|c|c|c|c|c|}
\hline \multirow[t]{3}{*}{ Test sample } & \multirow[t]{3}{*}{ Day } & \multirow{3}{*}{$\begin{array}{l}\text { Sample plate } \\
\text { code }\end{array}$} & \multirow[t]{3}{*}{$M_{\mathrm{s}}(\mathrm{g})$} & \multirow{3}{*}{$\rho_{\left(\mathrm{kgm}^{-3}\right)}$} & \multirow{3}{*}{$\begin{array}{l}C_{v} \\
\left(\mathrm{MJm}^{-3} \mathrm{~K}^{-1}\right)\end{array}$} & \multicolumn{4}{|c|}{$C_{s}\left(\mathrm{Jkg}^{-1} \mathrm{~K}^{-1}\right)$} \\
\hline & & & & & & \multicolumn{3}{|c|}{ Measured value } & \multirow{2}{*}{$\begin{array}{l}\text { Reference } \\
\text { value }\end{array}$} \\
\hline & & & & & & Trial 1 & Trial 2 & Mean & \\
\hline \multirow[t]{10}{*}{ Plastic (solid) } & \multirow[t]{5}{*}{1} & PS1 & 11.749 & 932.46 & 1.557 & 1668.24 & 1668.40 & 1668.32 & 1669.78 \\
\hline & & PS2 & 11.747 & 932.30 & 1.557 & 1672.19 & 1672.11 & 1672.15 & 1670.06 \\
\hline & & PS3 & 11.746 & 932.22 & 1.557 & 1672.99 & 1673.21 & 1673.10 & 1670.21 \\
\hline & & PS4 & 11.748 & 932.38 & 1.557 & 1670.98 & 1670.78 & 1670.88 & 1669.92 \\
\hline & & PS5 & 11.747 & 932.30 & 1.557 & 1672.89 & 1673.03 & 1672.96 & 1670.06 \\
\hline & \multirow[t]{5}{*}{2} & PS6 & 11.751 & 932.62 & 1.557 & 1669.52 & 1669.38 & 1669.45 & 1669.49 \\
\hline & & PS7 & 11.747 & 932.30 & 1.558 & 1674.20 & 1674.40 & 1674.30 & 1671.14 \\
\hline & & PS8 & 11.749 & 932.46 & 1.557 & 1670.97 & 1670.79 & 1670.88 & 1669.78 \\
\hline & & PS9 & 11.750 & 932.54 & 1.557 & 1669.88 & 1670.04 & 1669.96 & 1669.63 \\
\hline & & PS10 & 11.748 & 932.38 & 1.558 & 1673.23 & 1673.07 & 1673.15 & 1670.99 \\
\hline \multirow[t]{10}{*}{ Asbestos } & \multirow[t]{5}{*}{1} & AS1 & 23.043 & 1600.13 & 1.346 & 841.78 & 841.96 & 841.87 & 841.18 \\
\hline & & AS2 & 23.040 & 1600.00 & 1.346 & 842.90 & 842.76 & 842.83 & 841.25 \\
\hline & & AS3 & 23.044 & 1600.28 & 1.345 & 839.93 & 840.03 & 839.98 & 840.48 \\
\hline & & AS4 & 23.039 & 1599.93 & 1.346 & 843.95 & 844.07 & 844.01 & 841.29 \\
\hline & & AS5 & 23.041 & 1600.07 & 1.346 & 842.85 & 842.63 & 842.74 & 841.21 \\
\hline & \multirow[t]{5}{*}{2} & AS6 & 23.046 & 1600.42 & 1.345 & 839.64 & 839.86 & 839.75 & 840.40 \\
\hline & & AS7 & 23.041 & 1600.07 & 1.346 & 843.16 & 843.06 & 843.11 & 841.21 \\
\hline & & AS8 & 23.044 & 1600.28 & 1.345 & 842.10 & 841.94 & 842.02 & 840.48 \\
\hline & & AS9 & 23.040 & 1600.00 & 1.346 & 844.03 & 844.21 & 844.12 & 841.25 \\
\hline & & AS10 & 23.043 & 1600.21 & 1.346 & 841.97 & 842.21 & 842.09 & 840.51 \\
\hline \multirow[t]{10}{*}{ Paperboard } & \multirow[t]{5}{*}{1} & PB1 & 7.491 & 693.61 & 0.927 & 1339.91 & 1340.11 & 1340.01 & 1336.49 \\
\hline & & PB2 & 7.493 & 693.80 & 0.927 & 1336.29 & 1336.17 & 1336.23 & 1336.12 \\
\hline & & PB3 & 7.492 & 693.70 & 0.927 & 1336.97 & 1337.11 & 1337.04 & 1336.31 \\
\hline & & PB4 & 7.492 & 693.70 & 0.927 & 1337.10 & 1336.86 & 1336.98 & 1336.31 \\
\hline & & PB5 & 7.491 & 693.61 & 0.927 & 1339.83 & 1339.99 & 1339.91 & 1336.49 \\
\hline & \multirow[t]{5}{*}{2} & PB6 & 7.494 & 693.89 & 0.927 & 1336.79 & 1336.95 & 1336.87 & 1335.95 \\
\hline & & PB7 & 7.492 & 693.70 & 0.927 & 1337.56 & 1337.32 & 1337.44 & 1336.31 \\
\hline & & PB8 & 7.493 & 693.80 & 0.927 & 1337.43 & 1337.31 & 1337.37 & 1336.12 \\
\hline & & PB9 & 7.491 & 693.61 & 0.927 & 1341.01 & 1341.19 & 1341.10 & 1336.49 \\
\hline & & PB10 & 7.493 & 693.80 & 0.927 & 1336.91 & 1337.13 & 1337.02 & 1336.12 \\
\hline
\end{tabular}

Table 2 Values of specific heat capacity of the test sample for day 1 measurement

\begin{tabular}{lll}
\hline Test sample & \multicolumn{2}{c}{$\left(\mathrm{C}_{5}\left(\mathrm{~kg}^{-1} \mathrm{~K}^{-1}\right)\right.$} \\
\cline { 2 - 3 } & Mean measured value & Reference value \\
\hline Plastic (solid) & $1671.48 \pm 0.96$ & $1670.01 \pm 0.09$ \\
Asbestos & $842.29 \pm 0.81$ & $841.08 \pm 0.16$ \\
Paperboard & $1338.03 \pm 0.76$ & $1336.34 \pm 0.07$ \\
\hline
\end{tabular}

specific heat capacity values obtained on day 1 differ significantly from each other or even from those got on day 2 for each of the test samples. This simply means that both the SEUR's apparatus and KD2-pro meter give results of specific heat capacity measurements that are in good and strong agreement. By implication, the measured values of specific heat capacity recorded in this work for the test samples are valid and highly accurate.

More so, the measured values of specific heat capacity of the test sample plates for the trial runs on the 2 days considered in this work give reproducibility of $7.4 \%, 6.4 \%$, and $8.2 \%$ for the plastic, asbestos, 


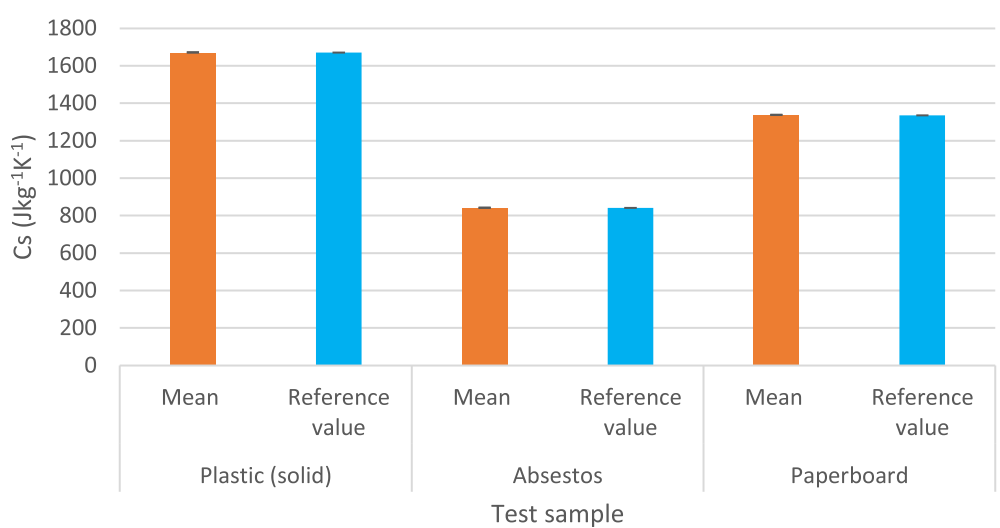

Fig. 3 Chart showing day 1 reference and mean measured specific heat capacity values of the test samples

and paperboard, respectively. With respect to the maximum value of $10 \%$ recommended as standard for unconditional acceptability of a test device or method [13], the values of reproducibility obtained in this work show that the SEUR's apparatus satisfies the condition for it to be a reliable apparatus for the purpose of determining specific heat capacity of bad heat conductors. As can be inferred from the results presented in Table 2, the percentage error in the mean specific heat capacity values of the plastic is $0.09 \pm$ $0.06 \%$ while that of the asbestos is $0.14 \pm 0.10 \%$ and the one for the paperboard is $0.13 \pm 0.06 \%$. These small error values are indicative of the fact that the measured values and reference values of the specific heat capacity obtained for the test samples are in good agreement, thereby confirming that the SEUR's apparatus has the needed reliability for its design purpose. Figure 3 compares the day 1 mean values of the specific heat capacities of each test sample used in this work. It is clear from the figure that the mean measured value is almost the same as the reference value for each of the samples. This portrays the fact that the specific heat capacity values determined by the use of the SEUR's apparatus can be relied upon for thermal characterization of thermal insulation materials.

\section{Conclusion}

At $\rho<0.05$, the experimental results obtained using the SEUR's apparatus showed very strong and positive correlation without any significant difference with the reference values determined by means of KD2-Pro meter. For both days, the maximum percentage error with respect to the reference value was found to be $0.17 \%$. Also, reproducibility values of $6.4 \%, 7.4 \%$, and $8.2 \%$ obtained in the case of plastic (solid), asbestos, and paperboard, respectively, were less than the maximum value of $10 \%$ recommended for unconditional acceptability of a test device. Generally, the SEUR's apparatus was found to be low-cost, easy to use, and suitable for quick determination of accurate, reliable, and valid specific heat capacity values of porous, non-porous, homogenous, or heterogeneous thermal insulators.

\section{Abbreviation}

SEUR's apparatus: Sunday Etuk Ubong Robert's apparatus

\section{Acknowledgements}

We would wish to thank the Editor and reviewer(s) for their inputs.

\section{Authors' contributions}

SEE: proposed the title, provided a detailed framework of the title, and designed the apparatus. UWR carried out the conceptualisation, construction, testing and calibration of the apparatus, and statistical analysis of results from testing of the apparatus. OEA carried out statistical analysis, sources for materials for literature review. All authors were involved in the writing and proofreading of the manuscript. All authors have read and approved the final manuscript.

\section{Funding}

No funding

\section{Availability of data and materials}

All data and materials used for this manuscript are found within the manuscript.

Ethics approval and consent to participate Not applicable.

\section{Consent for publication}

Not applicable.

\section{Competing interests}

The authors declare that there are no competing interests concerning the submitted manuscript.

\section{Author details}

${ }^{1}$ Department of Physics, University of Uyo, Uyo, Nigeria. ${ }^{2}$ Department of Physics, Akwa Ibom State University, Ikot Akpaden, Nigeria. ${ }^{3}$ Department of Physics, Michael Okpara University of Agriculture, Umudike, Nigeria. 
Received: 16 March 2020 Accepted: 2 June 2020

Published online: 01 September 2020

References

1. Tychanicz-Kwiecień M, Wilk J, Gil P (2018) Review of high-temperature thermal insulation materials. J. Thermophy Heat Transf. 33(11):1-12. https:// doi.org/10.2514/1.T5420

2. N. I. Inyang, Basic Practical Physics for schools and colleges, $1^{\text {st }}$ edn. Tribe Arts Agency, Ikot Ekpene, Akwa Ibom State, Nigeria, ISBN 978-33864-0-9, (2002) 74

3. E. N. Mgbenu, S. Ifedili, A. I. Menkiti, B. N. Onwuagba, Waves, optics and thermal physics, Nigerian University Physics Series Vol. 3, Africana-FEP Publishers Limited, Onitsha, Nigeria ISBN 978-175-308-0, (1999) 129 - 130.

4. J. O. Ebeniro, P. N. Okeke, K. D. Alagoa, O. N. Etim, M. N. Briggs-Kamara, D. D. Eya, F. M. Ezike, Preliminary practical physics manual, Physics writers series creation, Revised edn. Africana First Publishers PLC, Onitsha, Nigeria (2009) $111-112$.

5. Robert UW, Etuk SE, Umoren GP, Agbasi OE (2019) Assessment of thermal and mechanical properties of composite board produced from coconut (cocos nucifera) husks, waste newspaper and cassava starch. Int. J of Thermophy 40(83). https://doi.org/10.1007/s10765-019-2547-8

6. ASTM E1269 (2018) Standard test method for determining specific heat capacity by differential scanning calorimetry. ASTM international, West Conshocken, PA

7. ASTM D5334 (2014) Standard test method for determination of thermal conductivity of soil and soft rock by thermal needle probe procedure. ASTM international, West Conshocken, PA

8. Boro D, Kieno PF, Ouedrago E (2017) Experimental study of the thermal and mechanical properties of compressed earth blocks stabilized with sawdust according to the rates for the thermal insulation of a building. Int. J. Const. Eng. Mangt. 6(3):103-109

9. Oludotun JSO, Orji A, Ikpe AM, Ahmadu, HO (2011) STAN Physics for Senior Secondary Schools, New edn, HEBN Publishers PLC, Ibadan, Nigeria, ISBN 9789780814151. p. 125.

10. E. R. K. Rajput, Heat and mass transfer, Revised edn. S. Chand and Company PVT Itd, Ram Nagar, New Delhi, ISBN 978-81-219-2617-1, (2015), 30

11. Anyakoha MW (2013) New School Physics for Senior Secondary Schools, 4th end, Africana First Publishers PLC, Onitsha, Nigeria, ISBN 978-978-175-711-2. p. 214.

12. Robert UW, Etuk SE, Agbasi OE (2019) Modified water displacement method and its use for determination of bulk density of porous materials. J. of Renew, Eng. And Mech 1(01):1-16. https://doi.org/10.25299/rem.2019.Vol. 1(01).2292

13. Automotive industry action group, Measurement system analysis manual $1^{\text {st }}$ edn. (1990) 46

\section{Publisher's Note}

Springer Nature remains neutral with regard to jurisdictional claims in published maps and institutional affiliations.

\section{Submit your manuscript to a SpringerOpen ${ }^{\circ}$ journal and benefit from:}

- Convenient online submission

- Rigorous peer review

- Open access: articles freely available online

- High visibility within the field

- Retaining the copyright to your article

Submit your next manuscript at $\boldsymbol{\nabla}$ springeropen.com 